\title{
Evaluation of Low Resistivity Beds Using Nuclear Magnetic Resonance Log
}

\author{
HAMADA, G.M. AND AL-AWAD, M.N. \\ Petroeum Engineering Department, College of Engineering \\ King Saud University, Saudi Arabia
}

\begin{abstract}
The combination of conventional logs such as density, neutron and resistivity logs is proven to be very effective in the evaluation of normal reservoirs. For low resistivity reservoirs, however, an accurate determination of the petrophysical parameters with the conventional logs is very difficult. This paper presents some cases of low resistivity reservoirs and low contrast resistivity reservoirs where conventional logs fail to determine the petrophysical properties of formation. The problems of these reservoirs are that conventional logging interpretation shows high water saturation zones, but water free hydrocarbon would be produced. In case of low resistivity contrast reservoirs it is difficult to determine oil-water contact with resistivity logs. Nuclear magnetic resonance (NMR) log has been only available as a supplement tool to provide additional information on the producibility of the reservoirs. The main limitations of NMR logging, however, has been the cost and long time of acquiring data. This paper shows that, in the case of low resistivity reservoirs, NMR logging is a very effective tool, which helps to accurately determine the reservoir rock petrophysical properties. For the analysis of NMR data, several aspects of NMR technique have been used; 1) T1/T2 ratio, for fluid identification, 2) the difference between NMR derived porosity and total porosity, to determine the types of clay minerals, 3) NMR relaxation properties, to identify fluids nature and rock properties of low contrast / low resistivity reservoirs. This paper presents three examples of low resistivity reservoirs. Analysis of NMR data of low resistivity zones has helped to identify the producibility of these reservoirs zones, to determine lithology independent porosity and to distinguish between bound and free water. In case of low contrast resistivity reservoirs where there was little resistivity contrast between water bearing formation and oil-
\end{abstract}




\section{Introduction}

Information evaluation, resistivity logs are the main pay zones identifiers because of resistivity contrast between oil zone and water zone. If, however, a pay zone exhibits low resistivity, these logs become incapable of identifying the producing zones and also of indicating water mobility. Because of this limitation, many potentially productive zones with high irreducible water saturation are overlooked. Control of water production and identification of low resistivity pay zones with high irreducible water saturation of two formation evaluation problems are existing in many fields in the Middle East and other fields around the world.

There are many reasons leading to low resistivity pay zones. It is of crucial importance to know the origin of this phenomenon. The problem with these zones is that the resistivity data interpretation indicates high water saturation, but oil or even dry oil will be produced. The reasons for low resistivity phenomenon are classified mainly into two groups. The first group is concerned with reservoirs where the actual water saturation can be high, but water - free hydrocarbons are produced. The mechanism responsible for such high water saturation is usually described as being caused by microporosity. The second group is concerned with reservoirs where the calculated water saturation is higher than the true water saturation. The mechanism responsible for this high water saturation is described as being caused by the presence of conductive minerals such as clay minerals, metal sulfides, graphite and pyrite in a clean reservoir rock. Pyrite is a common heavy mineral associated with marine sedimentary rocks. It has a good electrical conductivity that is usually comparable to, or even higher than the conductivity of the formation water. The crystals of pyrite may form a continuous network even at low pyrite concentrations. Measured resistivity of dry pyrite ranges from 0.03 to $0.8 \Omega$. $\mathrm{m}$. Pyrite's conduction is of metallic (electronic) nature and consequently any transfer of current between water and pyrites is based on conversion from ionic to electronic conduction and vise versa. This leads to polarization at the waterpyrite interfaces with the corresponding frequency dependent electrical properties. Thus the electrical properties of porous rocks with pyrites are strongly dependent on the amount, distribution of pyrite and the measuring frequency of the electrical current. ${ }^{[1]}$ 
The problem of low resistivity reservoirs usually is not one of being able to determine the presence of hydrocarbons. Generally, standard log analysis will identify the hydrocarbon bearing zones. The problem is to be able to predict that little or no water will be produced even though log analyses indicate that the formation has high water saturation. The most promising candidate to solve this problem is the nuclear magnetic resonance log. NMR log can identify water free production zones, correlate bound fluid volume with clay minerals inclusions in the reservoir, and identify hydrocarbon type. ${ }^{[2-4]}$

The connection between NMR measurements and petrophysical parameters stem from the strong effect that the rock surface has on promoting magnetic decay of saturating fluids. The longitudinal relaxation time (T1) is the parameter of high interest for estimating petrophysical properties, but the NMR only measures the transverse relaxation time (T2) which is influenced by the inclusion of paramagnetic minerals such as (iron-bearing) chlorite in the low resistivity pay zones. La Torraca et $\mathrm{al}^{[5]}$ found that there are magnetic gradients between pore fluids and the iron bearing rock minerals. These gradients will make the diffusion movements of oil and water out of the frequency domain, resulting in faster T2 decay. This faster T2 decay will result in underestimation of the effective porosity and lead to difficulties in the determination of bound and free fluids.

The phenomenon of low contrast resistivity pay zones is encountered in reservoirs where there is little resistivity difference between water bearing and oil bearing zones. In low contrast resistivity reservoirs, the water-bearing zone contains relatively fresh water; thereby the resistivity is higher than normal. While in oil-bearing zone the associated water is a mix of fresh and salt water, so the resistivity is lower than normal and variable. Such oil reservoirs also show a high level of connate water saturation that causes a further depression of formation resistivity. Considering these two abnormal changes in water and oil zones, it will be quite difficult to identify the pay zone from resistivity log. The use of NMR log has clearly solved this problem. The problem is so-called low contrast resistivity reservoirs showing high contrast NMR relaxation times. ${ }^{[6]}$

This paper presents the wealth of information provided by NMR log to determine, more accurately than conventional logs, the petrophysical properties of low resistivity reservoirs. Three field examples will be presented; two examples are for low resistivity reservoirs and one example showing a low contrast resistivity reservoir. Before analyzing the field examples, the basic principles of NMR and their effect on the interpretation are discussed. 


\section{NMR Porosity}

The fact that NMR porosity depends only on the fluids content of the formation, unlike density/neutron porosity which is influenced by both fluids and surrounding rocks makes NMR measurements much more capable than conventional $\operatorname{logs}$ to furnish clay-corrected porosity, non-productive and productive porosities. The strength of the NMR signal is proportional to the number of hydrogen atoms in NMR tool dependent rock volume. In zones containing light hydrocarbon, where the hydrogen index is less than unity, NMR porosity will typically underestimate true porosity in proportion to the hydrogen index. In this formation there is a separation between density and neutron porosity, which indicates light hydrocarbon. For oil and water, NMR results can be expressed as percentage of fluid volume of the rock volume. The number of hydrogen atoms in gas depends strongly on temperature and pressure. Hence it is important to estimate accurately pressure and temperature to account for their effect on NMR results in natural gas reservoirs. ${ }^{[7-11]}$

In the literature, there has been some confusion in defining and using the results of NMR porosity data. To clear out this confusion, Figure (1) shows the standard rock porosity model for all pore fluids. MSIG denotes the total porosity. MPHI is the effective porosity from NMR (fluid fractions of rock),

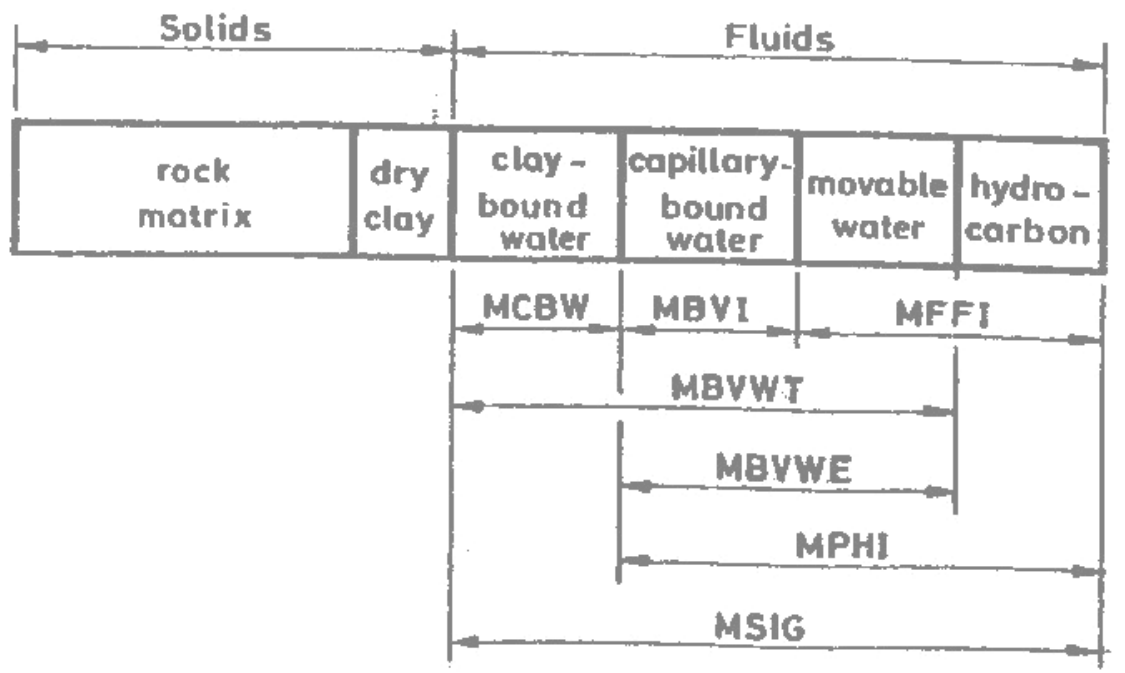

Fig.1 The standard rock porosity model for all pore fluids. ${ }^{[10]}$ (MSIG total porosity, MPHI effective porosity, MBVWE bulk volume water effective, MBVWT bulk volume water total, MBHI free fluid index, MBVI bulk volume irreducible water and MCBW clay bound water). 
except for clay bound fluids, with T2 above $3 \mathrm{~ms}$ ). MCBW represents the claybound water porosity with T2 $<3 \mathrm{~ms}$. MFFI, the free fluid index, which includes all movable fluids (hydrocarbon and free water) with $\mathrm{T} 2>33 \mathrm{~ms}$ in sandstone. MBVI, the capillary bound water, is defined as all porosities measured with T2 between 3 and 33 ms. MBVWT represents bulk volume of water (free, capillary and clay bound water).

\section{NMR and Fluids Type}

New methods for acquiring and processing NMR log data enable signals from gas, oil and water to be unambiguously separated and, in many cases, quantified. These methods exploit the combined effects of $\mathrm{T} 1$ and diffusion contrast based on log response. The T1 contrast separates the water and light hydrocarbon (oil and gas). Gas and oil signals are then separated based on the large contrast in the diffusion-induced T2 relaxation times for gas versus liquid. Figure (2) shows, in a qualitative way, NMR properties for water, oil and gas under typical reservoir conditions. Laboratory NMR data show that both T1 and T2 vary over several orders of magnitude depending on fluid type. Hence to allow reliable fluid typing, linear gradient field NMR tools have to be capable of measuring relaxation times from less than $1 \mathrm{~ms}$ to several seconds. ${ }^{[13-14]}$

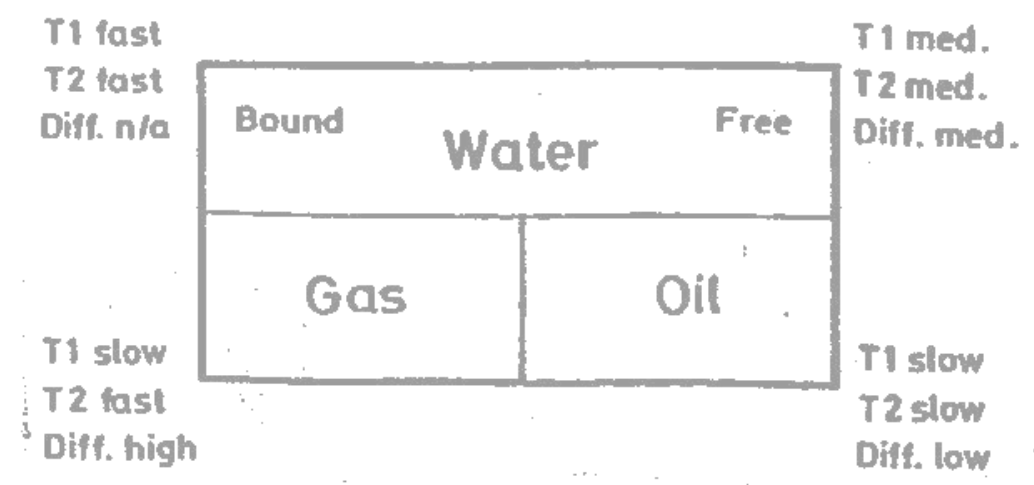

Fig.2 NMR parameters (T1, T2 and Diffusion) for water, oil and gas under reservoir conditions. ${ }^{[10]}$

Freedman et al ${ }^{[15]}$ has introduced a new method called Density- Magnetic Resonance (DMR) for evaluating gas-bearing reservoirs. The method combines total porosity from the NMR tool (TCMR) and density derived porosity 
(DPHI). The method provides gas - corrected total formation porosity and flushed- zone gas saturation. Gas corrected total porosity also improves permeability estimates using Coates-Timur equation in gas bearing formations

In certain cases of low resistivity reservoirs with water saturation greater than $50 \%$ and being able to produce water free hydrocarbon, this is attributed to the inclusions of clays. Generally standard log analysis will identify these reservoirs. But, the problem is how to be able to predict that little or no water will be produced. Zemanek ${ }^{3}$ has proposed certain technique to solve this problem. This technique was based on the comparison between irreducible water saturation (Swi) derived from laboratory NMR surface area to Swi and water saturation ( $\mathrm{Sw}$ ) deduced from conventional log analysis. If $\mathrm{Sw}$ is less than or equal to Swi, free water hydrocarbon will be produced and if $\mathrm{Sw}$ greater than Swi, water will be produced.

\section{Field Examples}

The movement of oil exploration into new areas is normally accompanied by new problems. Well log interpretation is not excluded. In the case of low resistivity reservoirs, resistivity logs analysis shows high water saturation but water free hydrocarbon will be produced. The standard logs fail to predict this phenomenon. This section presents different field examples to show how NMR log can help to solve this problem.

\subsection{Field Example 1}

Figure (3) shows a suite of logs from an offshore Gulf of Mexico well drilled in low- resistivity Pleistocene sandstone formation ${ }^{[3]}$. Water saturation calculations, from induction resistivity $\log$ and using resistivity exponents measured on 12 core samples, have shown that water saturation is generally greater than $50 \%$, where the water saturation values go from $25 \%$ to $74 \%$. Figure (4a) shows water saturation from induction $\log$ and density porosity as a function of surface area. The core analyses shows that these oil sands are not clean and that there are clay/silt size inclusions. The samples consist of 14 to $34 \%$ by weight of less than $30 \mu \mathrm{m}$ gain size material. These clays present high surface area on which water adheres, and the water, which is only of several molecular layers thick on the surfaces, is bound and cannot move. The induction $\log$ responds to the total water (free and bound); therefore, water saturation has exceeded $50 \%$ and water free hydrocarbons are produced. Capillary analyses of these dirty cores have shown high irreducible water saturation. The source of the high capillarity is the existence of large to moderate surface area clay minerals. Capillary attraction holds water to grain surface, hence, the actual water can be high, but dry oil is produced. 


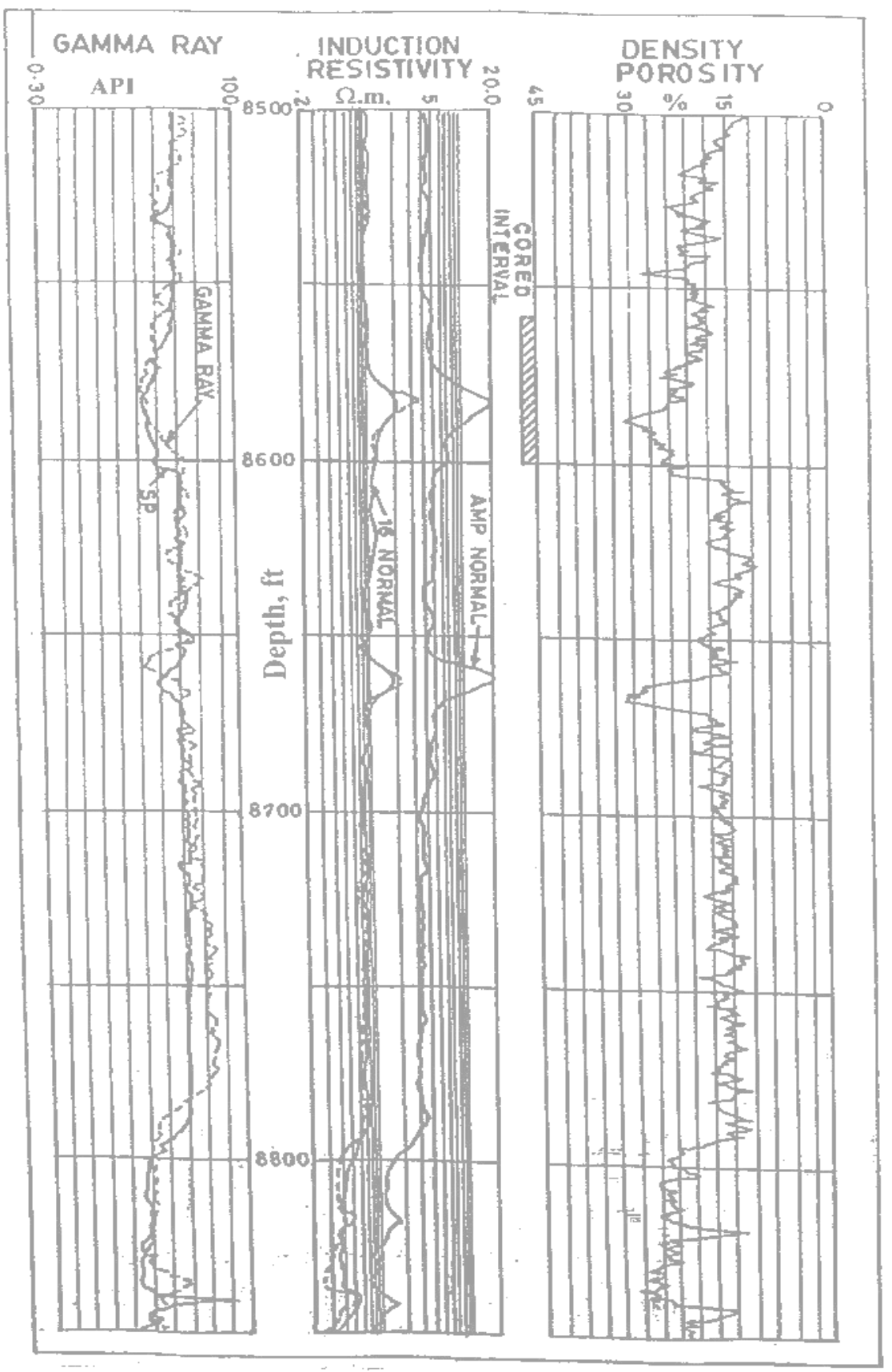

Fig.3 Logs for a well in low resistivity reservoir of Pleistocene Sandstone formation, (offshore Gulf of Mexico). ${ }^{[3]}$ 
The main problem is to predict the little or no water that will be produced even though log analyses indicate high water saturation. NMR measurements on sidewall core samples are the most readily technique to identify these low resistivity reservoirs. The proposed technique is applied in the study as follow: 1. NMR surface area measurements were conducted on the 12 core samples

2. Specific surface areas (As) using equation (As $\left.=A_{N M R}[(1-\phi) / \phi] \rho_{\text {ma }}\right)$ were calculated

3. $\mathrm{S}_{\mathrm{wi}}$ from capillary pressure curves is plotted versus As as shown in Figure (4b) The correlation equation between Swi and As for each sample is $\left.\mathrm{S}_{\mathrm{wi}}=1-\mathrm{e}^{(-0.0047 \mathrm{As}+0.24)}, \mathrm{r}=0.982\right)$ where $\mathrm{r}$ is the correlation coefficient.

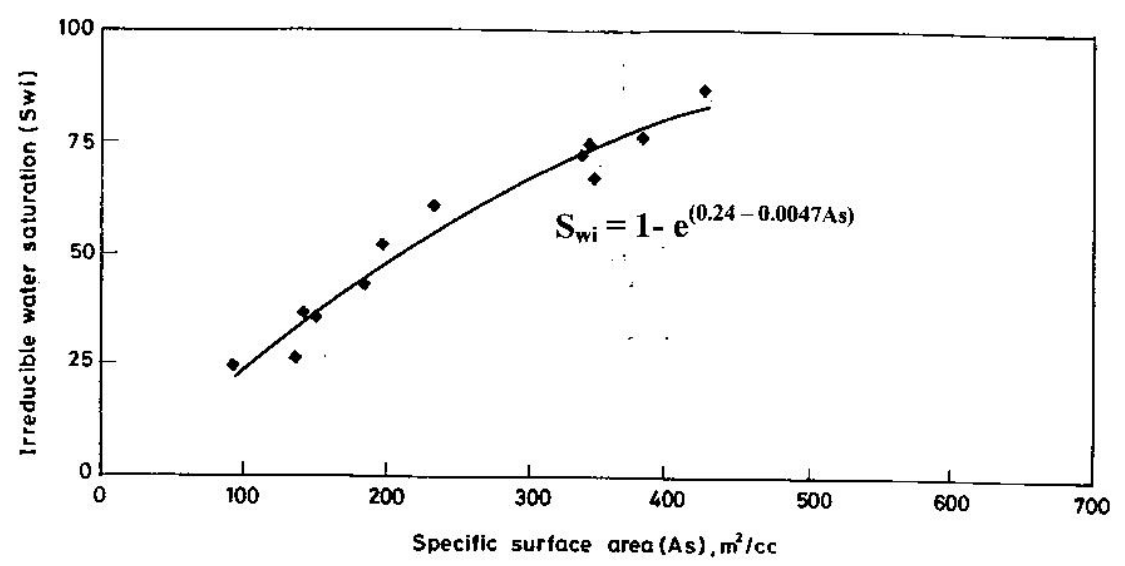

Fig.4a Water saturation from induction log versus grains surface area.

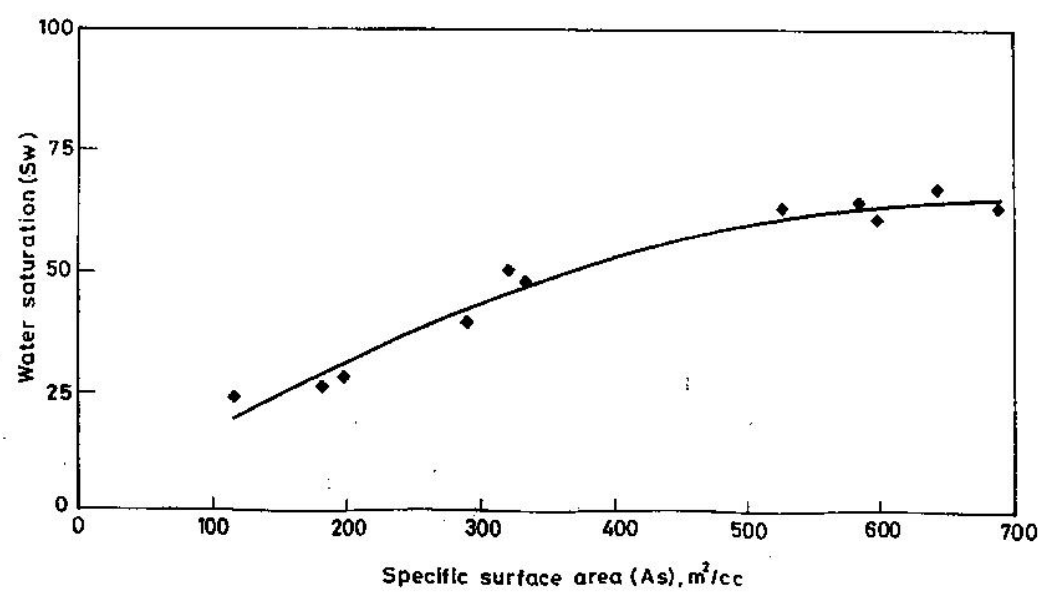

Fig.4b Irreducible water saturation versus grains surface area. 
4. Water saturation $\left(\mathrm{S}_{\mathrm{w}}\right)$ from induction $\log$ and density log data were found

5. Comparison between $S_{w}$ and $S_{w i}$, water free hydrocarbon will be produced over the interval where $S_{\mathrm{w}}<$ or $=S_{\mathrm{wi}}$. Water will be produced where $S_{\mathrm{w}}$ is $>S_{\mathrm{wi}}$. The comparison between Figures (4a) and (4b) shows that $S_{w}$ is generally less than $S_{w i}$, which indicate that this well section will produce water free hydrocarbon. This was confirmed when the well was tested and showed dry oil production.

The above approach-using laboratory NMR is recommended when the downhole NMR measurements are not available. To predict the probability of water production for a new well in the same low resistivity reservoir; start by steps 1 and 2, use correlation equation of step 3 and proceed steps 4 and 5 for the selected core samples.

\subsection{Field Example 2}

Figure (5) presents logging data for Abu-Gharadig gas well drilled in the Western Desert, Egypt. The main producing formation in this well is Middle Cretaceous Kharita formation which is a shaly sand formation ${ }^{16}$. This glauconitic sandstone is very heterogeneous; since it is a mixture of silt, very fine sands and glauconite. This complex lithology formation is characterized by high grain surface area, thus, its irreducible water saturation is high. Resistivity logs read about $1 \Omega . \mathrm{m}$. against pay zones and the log analyses have shown high water saturation $(80 \%-90 \%)$, however, the wells produce water free hydrocarbon. The main mechanism of such case is being the micoporosity and the high capillarity, ${ }^{[10]}$. The NMR data shown in Figure (5) indicates that there is a considerable amount of free fluid (gas and water) below depth $\mathrm{B}$ while there is very little free fluid above depth B as shown in track 2 . This was based on the cutoff value of $33 \mathrm{~ms}$ as shown in track 3 . The true porosity is derived from density log rather than NMR and neutron logs. At depth A all porosity logs (MSIG, PNSS and PDSS) are going down to about 10 p.u. while the true porosity is about 25 p.u. The case of this well is common in the Western Desert fields, thereupon, it is recommended to run NMR in new wells to better identify these low resistivity reservoirs.

\subsection{Field Example 3}

This is an example of low contrast resistivity in Early Cretaceous sandstone reservoir, Saudi Arabia, ${ }^{[6]}$. In such sandstone reservoirs, the water bearing formations contain relatively fresh water, thus show high resistivity. The pay zones contain mixed water (brine and fresh) which make formation resistivity variable and lower than the normal values. These sandstone reservoirs are characterized by high level of irreducible water saturation that 


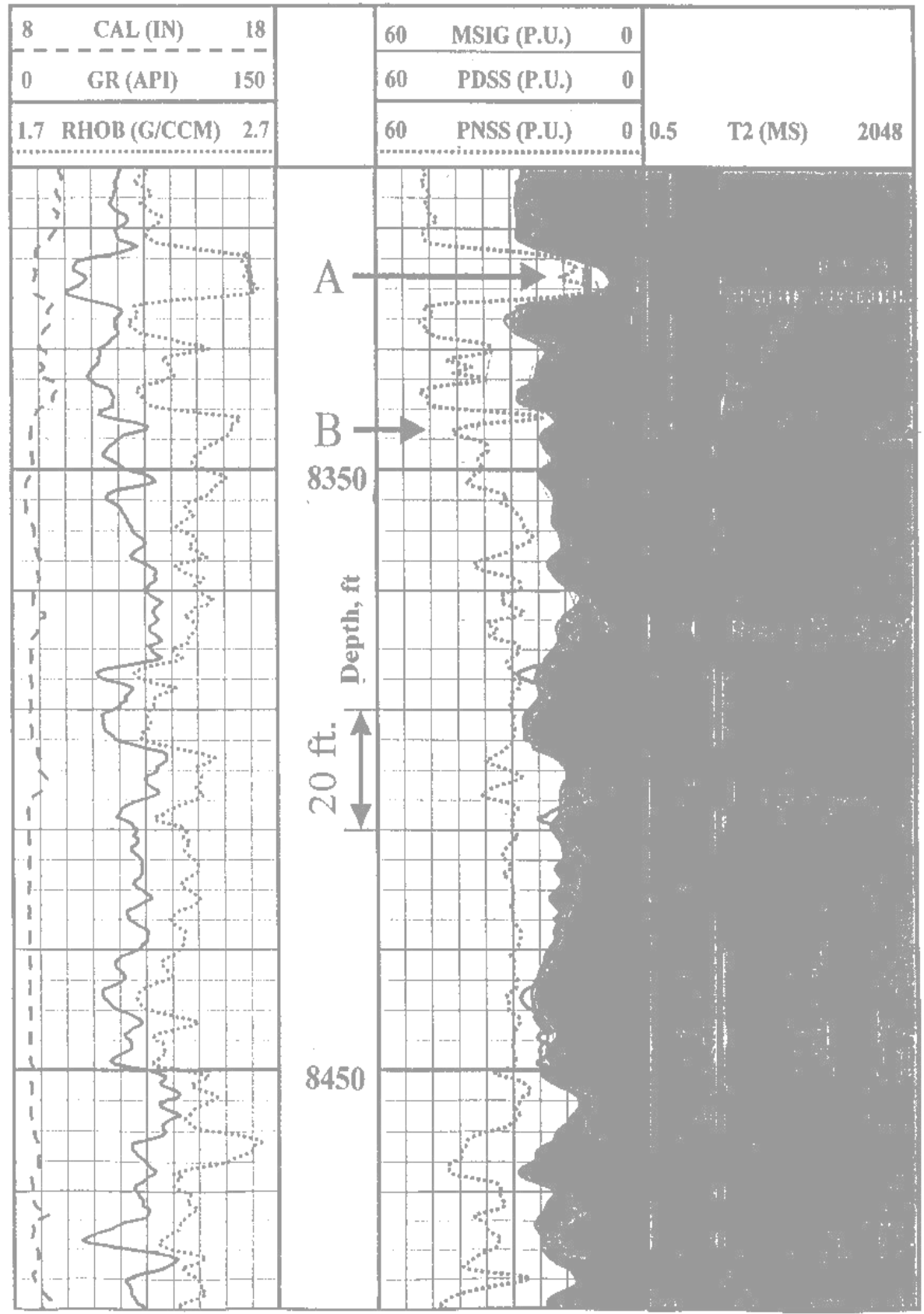

Fig.5 Logging suite for a gas well in low resistivity shaly sand reservoir (Abu Gharadig formation, Western Desert, Egypt) ${ }^{[6]}$. 
provokes more resistivity depression. The relatively high water zone resistivity and low pay resistivity created low contrast resistivity between pay zone and water zone. This low contrast resistivity makes the pay zone identification from resistivity log a very tedious job. Figure (6) presents a logging suite run in one oil producing well from a low contrast resistivity reservoir. In track 1, GR shows that there are three sand bodies and the resistivity reading in track 5 shows resistivity values in the range of 3-4 $\Omega$.m., which are typical resistivity values for water bearing zones in central Saudi Arabia fields ${ }^{[4]}$. This well is producing hydrocarbon with little water. NMR logging was used to solve this resistivity interpretation problem. The NMR logging technique works well in the low contrast resistivity reservoirs, based on the contrast in the relaxation parameters (T1, T2, and diffusion) between water (free and bound) and hydrocarbon (oil and gas), as shown in Figure (2). The technique of Modified

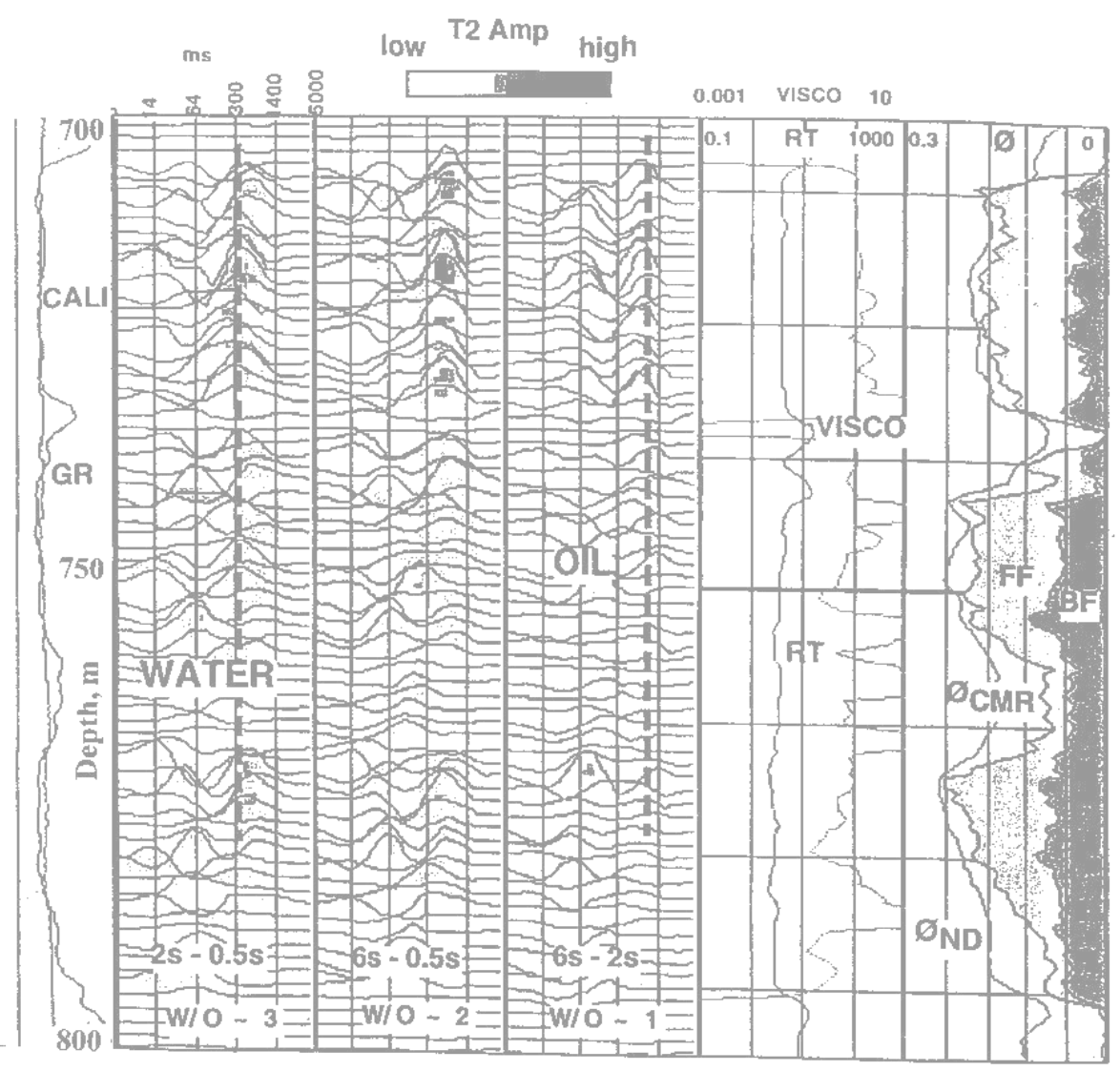

Fig.6 Modified differential spectrum and logging suite for a well in low contrast resistivity reservoir of Early Cretaceous sandstone oil formation (Saudi Arabia) ${ }^{[6]}$. 
Differential Spectrum $(\mathrm{MDS})^{[6]}$ was used to isolate water signal from hydrocarbon signal. The modified model has 3 passes at three waiting time groups. The use of MDS was to overcome the NMR interpretation problem due the absence of nearby water zone required to observe $\mathrm{T} 2$ distribution change between water zone and oil zone on the normal T2 distribution curve.

The illustrated model in Figure (7) was developed for $\mathrm{T}_{10 i l}=1.0 \mathrm{~s}$ and $\mathrm{T}_{1 \text { water }}=2.5 \mathrm{~s}$. The model includes three $\mathrm{T} 2$ distributions at $6 \mathrm{~s}, 2 \mathrm{~s}$ and $0.5 \mathrm{~s}$ waiting times (Figure7a-c) and 3 passes of MDSs with varying water/oil ratios (Figure7d-f). MDS have shown symmetrical spectrum around the peak at 300 $\mathrm{ms}$, in the case of water, for all waiting times which are shown by the broken curve in the models (Figures 7a-f). But in case of oil and water, the model spectrum (solid curve) lost symmetry and shifted, with respect to the ideal water peak, for all waiting time groupes, Figure 6.while the oil peak was observed at $1200 \mathrm{~ms}$. Neutron/density porosity (ND) and CMR porosity profiles are shown in track 6 . The three MDS passes shown in tracks 2,3 and 4 identified oil signal at $1200 \mathrm{~ms}$ and water signal at $300 \mathrm{~ms}$. Free fluid index shown in track 6 illustrates that oil will be produced. Formation tester was run afterward and confirmed oil in all three sand bodies. This example tested the ability of NMR log to identify oil zone already bypassed by resistivty log analyses and considered as water zone.

\section{Conclusions}

NMR technology proves to be very essential in formation evaluation and more specifically in low resistivity reservoirs. The capability of NMR to differentiate between movable and immovable fluids has helped the log analysts to get more accurate estimate of the reserves through the identification of low resistivity reservoirs that have already been bypassed by the resistivity logging interpretation. However, the interpretation of NMR data requires caution and experience to ensure that the suitable cutoff values are selected and that reliable conclusions are reached from the measured and calculated parameters especially in carbonate reservoirs.

The contribution of NMR information in the evaluation of the field examples discussed in this paper is twofold. Firstly, NMR helped to identify low resistivity reservoirs and low contrast resistivity reservoirs. Such reservoirs have not been often identified, heretofore, with resistivity data interpretation. Secondly, NMR can provide 1) detailed porosity information, and thus it can replace conventional porosity logs as porosity tool and fluids type identifier, 2) quantitative information about pore fluids (clay bound water, capillary bound water, free water, oil and gas) and 3) prediction of little or water free oil production even though the resistivity log indicates high water saturation. 

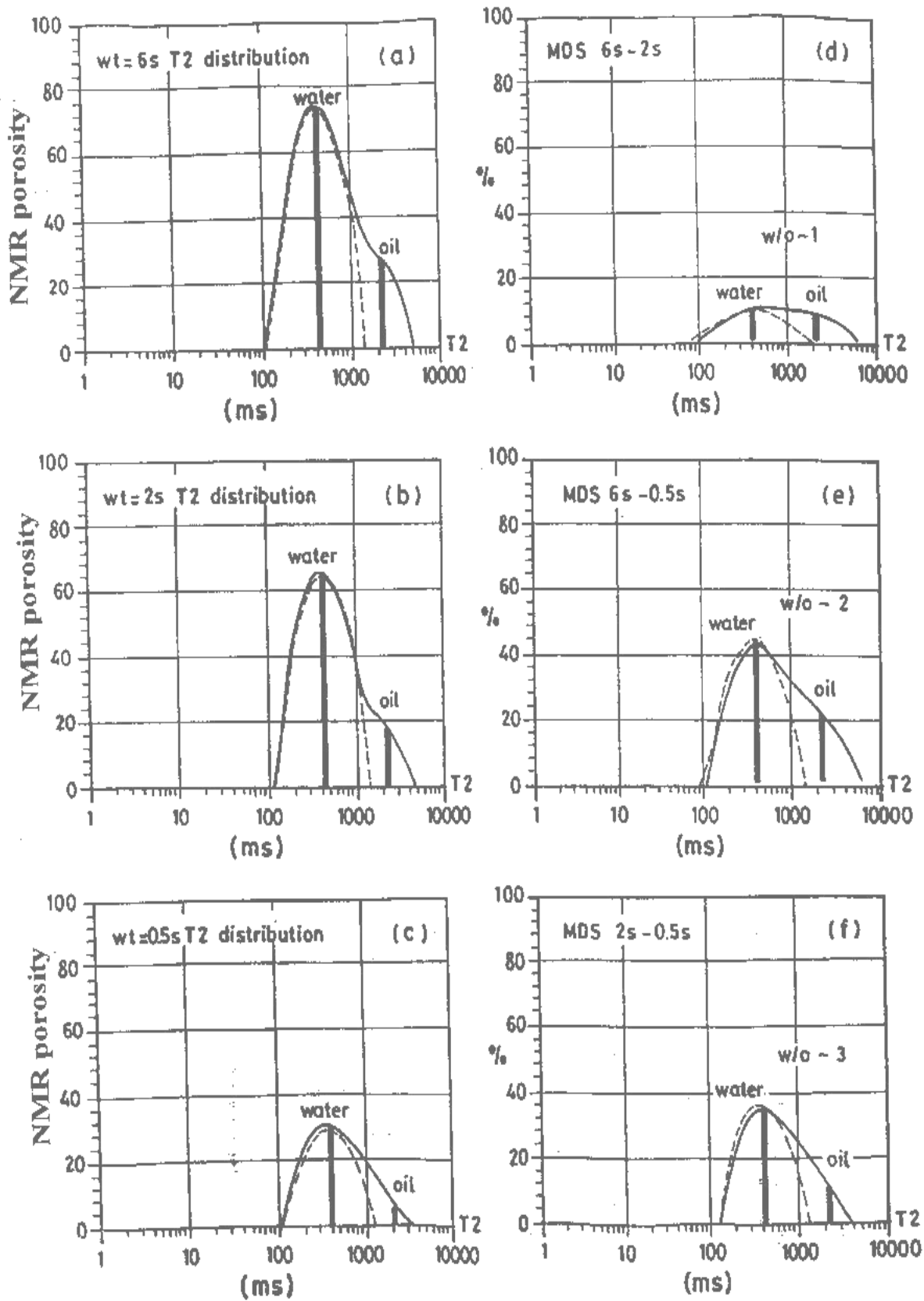

Fig.7 Modified differential spectrum (MDS) and T2 distribution at different Waiting time groups $(\mathrm{wt})$ and varying water/oil ratio for well in low contrast resistivity reservoir. 


\section{References}

[1] Clavier, C., Coates, G. and Dumanoir, J., The theoretical and experimental basis for the dual water model for the interpretation of shaly sand: The Log Analyst, Vol. 24, pp. 153-168.,1984.

[2] Murphy, R.P. and Owens, W.W., A New approach for low resistivity sand $\log$ analysis, JPT, p. 1302-1306.,1972.

[3] Zemanek, J. , Low Resistivity Hydrocarbon Bearing Sand Reservoir: JPTFE, pp. 515-521.,1989.

[4] Hamada, G.M. and Al-Awad, M.N.J. , Petrophysical evaluation of low resistivity sandstone reservoirs: SCA 9851, 1998 International Symposium of Core Analysts, The Hague, September 14-16, 1998.

[5] La Torraca, G.A., Dunn, K.J. and Bergman, D.J. (1995) Magnetic susceptibility contrast effects on NMR T2 logging. SPWLA 36th Annual Logging Symposium, Paris, June 26-29, 1995.

[6] Hassoun, T.H. and Zainalabedin, K., Hydrocarbon detection in low contrast resistivity pay zones, capillary pressure and ROS determination with NMR Logging in Saudi Arabia. SPE Paper 37770, 10th MEOS, Bahrain, March 15-18, 1997.

[7] Ayan, C., Haq, S.A., and Boyd, A., Integration of NMR, wireline tester, core and open hole log data for dynamic reservoir properties. SPE Paper 53273, 10th MEOS, Bahrain, March 15-18,1997.

[8] Akkurt, R., Vinegar, H.J., Tutunjian, P.N. and Guillorty., NMR Logging of natural gas reservoir: The Log Analyst Vol. 37, No. 6, pp. 33-42.,1996.

[9] Oraby, M, Habib, E. and Negm, E., Experience in permeability calculation in the Obayied field (Egypt) using magnetic resonance imaging. SPE Paper 53277, 10th MEOS, Bahrain, March15-18.,1997.

[10] Menger, S. and Prammer, M. " Can NMR porosity replace conventional porosity in formation evaluation. SPWLA 39th Annual Logging Symposium, Keystone,Paper RR, May 26-29.,1998.

[11] Slot-Petersen,C., Eidsemo, T., White, J. and Rueslatten, H.G., NMR formation evaluation application in a complex low resistivity hydrocarbon reservoir. SPWLA 39th Annual Logging Symposium, Paper TT, Keystone, May 26-29.,1998.

[12] Timur, A., Effective porosity and permeability of sandstones investigated through nuclear magnetic principles: The Log Analyst, Vol. 10, No. 1, pp. 311,1969 .

[13] Coates, G.R., Menger, S. and Miller, D., Applying total and effective NMR porosity to formation evaluation: SPE Paper 38736, SPE Annual Technical Conference and Exhibition.,1997.

[14] Hamada, G.M., Al-Blehed, M.S. and Al-Awad, M.N.J., NMR logs find reservoirs by-passed by conventional analysis, Oil \& Gas Journal Sept 27, p. 76-80.,1999.

[15] Freedman, R., Chanh,C.M., Gubelin, G.,Freeman, J.J., McGinnes, T., Terry,B. and Rawlence, D., Combining NMR and porosity logs for petrophysical analysis in gas bearing formation. SPWLA 39th Annual Logging Symposium, Paper II, Kaystone, May 26-29, 1998.

[16] Kenawy, F.A., Exploitation of Abu Gharadig field, Western Desert, Egypt. SPE Paper 18607, SPE International Meeting of Petroleum Engineering, Tianjin, Nov.1-4, 1998. 


\section{قوويم الطقبت الرملية منغفضة المقاومة الكهربية بلستخدلم تسجيلات الرنين المغنطيسي المناوية}

$$
\text { غريب مصطف حمادة ومساعد ناصر العواد }
$$

المستخلص : قد أثبتتطررق التسجيلات المستخمة كفاعة مقبولة في

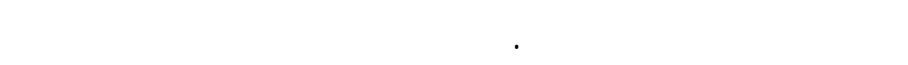

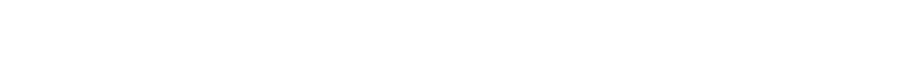

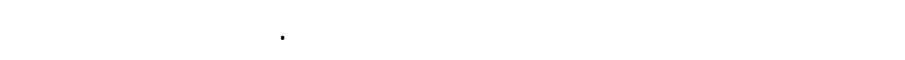
الرنين المغنلطيسي هسلب وبدقة المسلمية الفعلية ونوعية اللد ـوالل

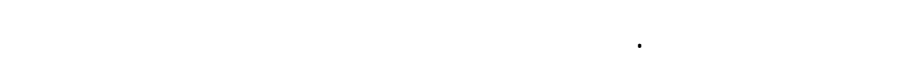

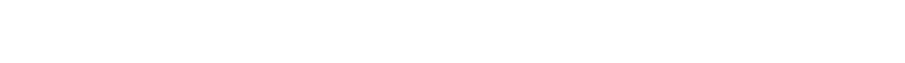

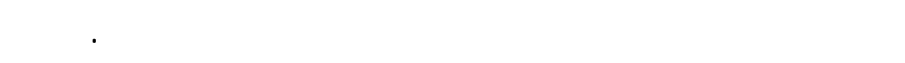

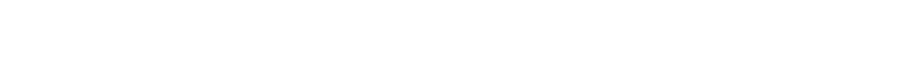

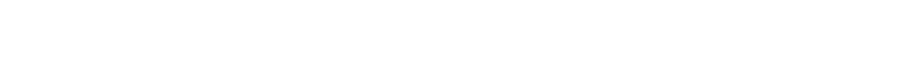
أو نلك التي لا قطهر تباينًا كهربيًا مع الطقات المات المائية المجاورة . 